\title{
Positive Emotions, Resilience and Psychosomatic Heath: Focus on Hellenic Army NCO Cadets
}

\author{
Konstantinos Karampas, Galanakis Michael, Anastasios Stalikas
}

Department of Special Education, University of Thessaly, Volos, Greece

Email: galanakismichael@hotmail.com

How to cite this paper: Karampas, K., Michael, G., \& Stalikas, A. (2016). Positive Emotions, Resilience and Psychosomatic Heath: Focus on Hellenic Army NCO Cadets. Psychology, 7, 1727-1740.

http://dx.doi.org/10.4236/psych.2016.713162

Received: September 23, 2016

Accepted: November 19, 2016

Published: November 22, 2016

Copyright $\odot 2016$ by authors and Scientific Research Publishing Inc. This work is licensed under the Creative Commons Attribution International License (CC BY 4.0).

http://creativecommons.org/licenses/by/4.0/

\begin{abstract}
Cadets $(n=395)$ of the Hellenic Army NCO Academy completed measures of Positive and Negative Affect, General Health and Resilience. Analysis revealed that positive emotions significantly correlate with higher level of resilience and better psychosomatic health, while negative emotions correlate with lower level of resilience and poor psychosomatic health. Furthermore, resilience strongly correlates with better psychosomatic health. Results also suggest that women cadets and freshmen are using positive emotions and develop resilience, as an adaptive strategy for coping with the high physical and mental demands of the Military Academy. These results contribute to a better understanding of the relationship between positive affections and resilience as well as the effect of these variables on psychosomatic health, in an eminently stressful environment such as Military Academies.
\end{abstract}

\section{Keywords}

Resilience, Positive Emotions, Psychosomatic Health, Cadets

\section{Introduction}

In the framework of Positive Psychology (Seligman \& Csikszentmihalyi, 2000), concepts such as positive emotions and resilience have been studied in social, work, and economic contexts because of their ability to equilibrate the negative effects of anxietyrelated experiences, which can influence negatively one's performance, psychosomatic health and psychological wellbeing.

Army and especially the sector of Military Academies, is an interesting field to study such concepts, because they require high mental and physical standards for their cadets (Matthews, 2008). Those standards test the limits of cadets in the framework of their military edification, in order to create skilful leaders both in war and peace. Therefore, this is the best framework to study human behaviour and resilience under extremely 
stressful conditions (Bartone \& Priest, 2001).

The aim of the present study is to investigate the relation between positive emotions and resilience as well as the effect of these variables on the psychosomatic health under the stressful conditions produced by the environment of an NCO Military Academy.

\section{Literature Review}

\subsection{Positivity}

Fredrickson (2005) introduced the basic concept of Positive Psychology, the concept of positivity. This concept refers to physical, cognitive, and emotional condition of people that are in positive mood or experience positive emotions such as love, happiness, caring, gratitude, inspiration, calmness, hope, pride, and awe (Fredrickson \& Losada, 2005). Positivity is the natural counter effect of negativity, and it is more than simple satisfaction provided by human senses, since positivity expands the attention of individual and so the provided satisfaction, lasts (Fredrickson \& Losada, 2005). Positive emotions also operate as regulators of anxiety levels and these affections consist a predictor for the development and the maintenance of psychosomatic health (Folkman \& Moskowitz, 2000; Affleck \& Tennen, 1996). In addition, individuals who experience positive emotions, exhibit excellent physical health and lower number of bad somatic symptoms (Lyubomirsky, Tkach, \& DiMatteo, 2006; Mroczek \& Spiro, 2005). More specific, positive emotions fight against the negative psychological effects of negative emotions (Undoing hypothesis) (Fredrickson \& Levenson, 1998, Fredrickson, Mancuso, Branigan, \& Tugade, 2000), they also reinforce the conscious confrontation of adversity (Fredrickson, Tugade, Waugh, \& Larkin, 2003; Tugade \& Fredrickson, 2002), they can operate as preventive factor in coping with depression (Fredrickson, Tugade, Waugh, \& Larkin, 2003), they can lead to psychological wellbeing through upward spiral mechanisms (Fredrickson \& Joiner, 2002; Tugade \& Fredrickson, 2002), as well they contribute to the increment in the levels of optimism, calmness and resilience (Fredrickson, Tugade, Waugh, \& Larkin, 2003).

\subsection{Resilience}

Resilience is one of the most effective natural defence mechanisms of the individual (Masten \& Reed, 2002), which is considered as capable to react efficiently with adversity and sometimes, thrive. This natural resilience is a combination of personal characteristics and individual skills, and this quality mixture can further developed, independently from its start point (Maddi \& Khosaba, 2005). However, resilience is a very perplexing concept and it appears to emerge from processes and interactions which are not under individual's control, since they are mostly influenced by the situations, the context and the environment (Masten \& Wright, 2010).

In literature it does not exist a uniform definition for resilience, since this is based on the way that this concept is approached and quantified. However, resilience is directly related to various forms of adversity or crisis and refers to the ability of the individual to recover from emotional negative or traumatic experiences as well to adopt well and 
positive on stressful experiences (Block \& Block, 1980; Block \& Kremen, 1996; Lazarus, 1993).

Resilient individuals, in comparison with individuals with lower level of resilience, do recognize the negative effects of stressful experiences (such as anxiety, anger, aggressiveness and disappointment), however, they evaluate such events as less threatening and they confront them as challenges,while also being more likely to find positive meaning through negative experiences (Tugade \& Fredrickson, 2004). Additionally, it appears that resilience is reflected strongly on mental health (Tugade \& Fredrickson, 2004), since individuals with higher level of resilience are dealing with adversity more effectively (Bonanno et al., 2007), they are also more protected against depressive symptomatology and they can improve their psychosocial function (Pietrzak et al., 2010).

Finally, resilience is not only a psychological phenomenon, but it has also a strong impact on physical health, as it helps the body functions (such as cardiovascular) to quickly recover to normal levels after a negative experience (Tugade \& Fredrickson, 2004).

\subsection{Positive Emotions and Resilience}

Theory indicates a strong relationship between positive emotions and resilience while positive emotions are more common among individuals with high level of resilience (Fredrickson, 1998, 2001). Moreover, positive emotions actually feed the resilience, since resilient individuals make use of positive emotions in order to recover from stressful situations and to find a positive meaning in such events, while the adaptive benefits of positive emotions are greater when individuals are under stress (Tugade \& Fredrickson, 2002, 2004). Moreover, resilient individuals appear to maintain a more optimistic, enthusiastic and energetic life attitude while they are more curious and open to new experiences and further characterized by higher positive emotionality (Block \& Kremen, 1996; Klohnen, 1996).

In addition, the experience of positive emotions contributes to the selection and usage of more adaptive strategies to cope with adversity, while those coping strategieshave a protective functionagainst anxiety and depression (Davis, Nolen-Hoeksema, \& Larson, 1998).

A possible explanation as to why positive emotions can have an adaptive value in the midst of stressful situations, it is offered by the broaden and build theory of positive emotions (Fredrickson 1998, 2001). This theory connects, in a causal way, positive emotions with the attainment and increment of resilience and psychological well-being.

According to this theory, positive and negative emotions have the same significant adaptive value, however negative emotions can decrease one's thought-action repertoire, leading to specific and predictive reactions (e.g. attack when angry, escape when afraid). Positive emotions on the other hand (such as love, happiness, caring, gratitude, inspiration, calmness, hope, and pride), operate as an antidote to the impact of negative emotions and broaden one's thought-action repertoire, leading to the building of strong physical, social, mind and psychological related sources, activating a long-lasting upward spiral (Fredrickson 1998, 2001). 


\subsection{Army Related Stressors}

Bartone and Priest (2001) emphasized that Military life is a concept that is associated with changes and transitions. According to Williams (1999), most transitions are associated with significant life events and changes to the individual's role or environment. These transitions have been recognized by Hobson et al. (1998) as the primary cause of stress and even though these significant events are considered as inevitable and repeated, however, the military way of life is leading to more frequent and simultaneous transitions.

Therefore, the admission of cadets to Military Academies leads to significant changes on their life style which is associated to changes on their relations, the removal of reinforcement and relief sources and the stressful requirement for a rapid adaptation. The provided training by Military Academies, which is conductedsimultaneously in academic and military level, require strong psychological and physical strength, while, in the framework of the Military edification, the limits of cadets are continuously tested, in order to build the personality and aptitudes that will be the necessary skills for their career.

More specifically, it has been found that the transition from civilian to military life as well as the military training itself is strong anxiety factors for cadets (Gold \& Friedman, 2000; Myers \& Bechtel, 2004). Also about the role of gender, according to research on male and female freshmen cadets of US Military Academy at West Point, it was found that female cadets were significantly higher in hardiness than males, although females also reported higher levels of stress in multiple aspects as well higher number of problems related to their physical health (Bartone \& Priest, 2001).

However, a key question that arises is why some cadets in these extreme stressful conditions manage to adapt, develop and mature, while others do not. What really distinguishes those who can from those who cannot stand.

Possible answers to these questions is given through the theory and research of resilience and positive emotions, which both buffers the real and perceived stress, interpret crisis as an opportunity and operate as indicators of psychosomatic health, leading to psychological well-being.

More specific according to Tugade \& Fredrickson (2004), positive emotions have a special beneficial effect on stressful conditions. Riolli, Savicki, \& Spain (2010), by investigating this topic in real situation of high stress, they studied soldiers of US Army which has served on Iraq, and they confirmed that positive emotions play a very important role against traumatic stress.

On the other hand, resilience, as a powerful process of positive adjustment in a stressful environment (Luthar, Cicchetti, \& Becker, 2000), consists the main factor for decreasing the stress impact of great changes-transitions that it is occurring on the admission of freshmen in Military Academies.

\subsection{Comprehensive Soldier and Family Fitness (CSF2)}

A good example of practical application for the aforementionedconcepts is the Com- 
prehensive Soldier Fitness (CSF) program in US Army. CSF program is based on theoretical framework of Positive Psychology and was originally established in 2008 (General Casey, 2011) and renamed in 2012 as Comprehensive Soldier and Family Fitness (CSF2). The aim of this program is to build the culture of resilience in US Army and enhance performance of the Soldiers, their Families, and Army Civilians, as well to decrease the rate of maladaptive reactions (Cornum, Matthews, \& Seligman, 2011).

Based on the research cited above, our hypotheses to this study are as follows:

Hypothesis 1: It is expected statistical significant and positive correlation between resilience and positive emotions and a negative correlation with negative emotions.

Hypothesis 2: It is expected statistical significant and positive correlation between resilience and positive emotions and psychosomatic health and a negative correlation between negative emotions and psychosomatic health.

Hypothesis 3: It is expected non-significant mean differences on resilience and positive emotions based on gender. However, it is hypothesized that female cadets will exhibit statistically significant more psychosomatic health problems in GHQ-28, compared with male cadets.

Hypothesis 4: It is expected non-significant mean differences between positive emotions and the academic year in the NCO Military Academy. However, it is expected statistically significant mean differences on resilience and psychosomatic health based on the Academic year of cadets.

\section{Method}

\subsection{Participants and Procedures}

The present study used a sample of 395 cadets that was drawn from two classes of the Hellenic Army NCO Academy. The sample included 272 males and 123 females, aged 18 - 22 years old, with a mean of age 19.5 years. Moreover, 214 were $1^{\text {st }}$ year cadets and 181 were $2^{\text {nd }}$ year cadets.

After permission was granted from the Hellenic Army General Staff for that study, questionnaires were given to the cadets of the Hellenic Army NCO Academy. The participants were briefed about the questionnaires, the duration of the process and their anonymity. The questionnaires were self-reported while only the researcher was present during questionnaire completion process which lasted about half hour.

\subsection{Measures}

The following questionnaires were selected as appropriate to our sample, because they can measure in a satisfying degree the variables of this study:

1) Connors-Davidson Resilience Scale (CD-RISC: Connor \& Davidson, 2003)].

The Connors-Davidson Resilience Scale (CD-RISC) is a short self-report questionnaire that it can measure Resilience and it is consisted of 25 items which are rated on a 5-point Likert scale (0 - 4). Higher scores on that scale correspond to higher Resilience. This scale presents a good convergent and divergent validity as well reliability (Cronbach $\mathrm{a}=.89$ ) as well a good test-retest reliability (inter-correlation coefficient $=.87$ ) 
(Dimitriadou \& Stalikas, 2011). It must be noted that CD-RISC also includes items that correspond to Hardiness (Kobasa, 1979) concept's dimensions such as control, commitment and challenge (Connor \& Davidson, 2003).

2) Positive and Negative Affect Scale (PANAS: Watson et al., 1988)

The concept of positive mood (positive affect), is referred to the frequency and intensity of the positive mood and positive emotions that the individual tends to feel (Watson et al., 1988). The Positive and Negative Affect Scale (PANAS: Watson et al., 1988) has been translated and standardized in Greece by Dascalou and Sygkollitou (2011). At the Positive and Negative Affect Scale, cadets are evaluating in a 5-point Likert scale (from $1=$ not at all to $5=$ Extremely), the degree which they feel a number of emotions during a week and it is consisted of 10 items that correspond to Positive Affection (P.A) and 10 items that correspond to Negative Affection (N.A). As positive emotional state is defined the positive interaction of the individual with the environment, the pleasant occupation with activities, the positive energy and enthusiasm. The negative emotional state is defined as the interaction with the environment that is manifested by emotions of anxiety, fear, and anger (Dascalou \& Sigkollitou, 2011). When the scale of positive and negative affection is administered with short-term instructions tend to be sensitive to fluctuations of mood while the long-term instructions show better attributes about stability of the mood (Dascalou \& Sigkollitou, 2011). For the aim of the current study, the long-term instructions were selected.

3) The General Health Questionnaire-28 (GHQ-28: Goldberg \& Hillier, 1979)]

The General Health Questionnaire-28 (Goldberg \& Hillier, 1979), is the updated form of GHQ-60 and it is a widely used self-report questionnaire, which can assess the psychological health of adults as well as to detect psychological disorders and nonsevere psychopathological problems in the general population. The internal reliability of the original edition, according to Goldberg is Cronbach's alpha $=0.94$, while according to Garyfallos et al. (1991), in the Greek translated edition of GHQ, has a Cronbach's alpha of 0.93 . The questionnaire includes 28 close-ended questions which assess the current psychological health and the existence of various psychological discomforts in adult's normal activities, performance, emotions for the life and self-esteem. These questions consist of 4 subscales and each subscale includes 7 questions. These subscales are about: a) Somatic Symptoms, b) Anxiety/Insomnia, c) Social Dysfunction and d) Severe Depression. Participants must assess if the symptom or the behaviour, that is described by these questions, is present to the participant: not at all, same as usual, more than usual, much more than usual (scale from 1 to 4 ). The questionnaire reports a total score of general health of the adult, as well scores for each subscale of it. Lower scores on subscales show better general health of the participant. It must be noted that the subscales of GHQ-28 represent only the dimensions of the corresponding symptomatology and they do not consist distinct diagnosis.

\subsection{Statistical Analysis}

Analyses were conducted using SPSS software (Version 19). Pearson correlation coeffi- 
cient was calculated to control the correlations between the variables of positive and negative emotions, resilience and psychosomatic health. T-test for independent samples was applied to compare the general health with gender and academic year variables. Stepwise multiple regression analyses were conducted with positive emotions, negative emotions and resilience as predictor variables and psychosomatic health as predictive variable and also with psychosomatic health, positive emotions and negative emotions as predictor variables and resilience as predictive variable. Statistical significance was set at $(p<.05)$.

\section{Results}

It was found statistically significant of medium power linear correlation between resilience (CD-RISC) and positive emotions (PANAS-P) $(\mathrm{r}=.547, p=.000)$ and weak negative correlation of resilience (CD-RISC) with negative emotions (PANAS-N) $(r=-.236$, $p=.000$ ) (Table 1 ), showing that positive emotions are correlated statistically significant with higher level of resilience while negative emotions are correlated statistically significant with lower level of resilience for the current sample. Additionally, it was found statistically significant of medium power negative correlation between general health (GHQ-28) and resilience (CD-RISC) ( $\mathrm{r}=-.479, p=.000)$, which shows that as resilience is increasing (CD-RISC), the scores on GHQ-28, are decreasing, showing a better psychosomatic health for the participants.

Finally, it was found statistically significant of strong power, positive correlation between general health (GHQ-28) and negative emotions (PANAS-N) $(\mathrm{r}=.604, p=.000)$, as well a statistically significant of medium power, negative correlation between general health (GHQ-28) with positive emotions (PANAS-P) $(\mathrm{r}=-.412, p=.000$ ), which means that positive emotions are correlated statistically significant with better psychosomatic health, while negative emotions are correlated statistically significant with worse psychosomatic health.

The linear correlation of the General Health Questionnaire (GHQ-28) subscales and the scales of Positive and Negative Affections (PANAS), using Pearson (Table 2), found that there is statistically significant and negative correlation between the subscale of GHQ-28, "somatic symptoms", and resilience $(\mathrm{r}=-.367, p=.000)$, between the subscale "anxiety/insomnia" and resilience $(\mathrm{r}=-.442, p=.000)$, between the subscale "social dysfunction" and resilience $(\mathrm{r}=-.416, p=.000)$, as well between the subscale of "severe depression" and resilience $(\mathrm{r}=-.479, p=.000)$.

Table 1. Correlations (pearson) between the general health, resilience and positive/negative emotions.

\begin{tabular}{ccc}
\hline & General health & Resilience \\
\hline Resilience & $\mathrm{r}$ & $\mathrm{r}$ \\
Positive emotions & $-.479^{* *}$ & \\
Negative emotions & $-.412^{* *}$ & $.547^{* *}$ \\
\hline
\end{tabular}

${ }^{* *} p<.01$. 
Table 2. Correlations (pearson) between the subscales of general health, resilience, positive and negative emotions.

\begin{tabular}{cccc}
\hline & Resilience & Positive emotions & Negative emotions \\
\cline { 2 - 4 } & $\mathrm{r}$ & $\mathrm{r}$ & $\mathrm{r}$ \\
\hline Somatic symptoms & $-.367^{* *}$ & $-.219^{* *}$ & $.585^{* *}$ \\
Anxiety-insomnia & $-.442^{* *}$ & $-.470^{* *}$ & $.310^{* *}$ \\
Social dysfunction & $-.416^{* *}$ & $-.244^{* *}$ & $.497^{* *}$ \\
Severe depression & $-.479^{* *}$ & $-.391^{* *}$ & $.604^{* *}$ \\
\hline
\end{tabular}

${ }^{\star} p<.05 .{ }^{* *} p<.01$.

Moreover, it was found statistically significant of medium to strong power, positive correlation between the subscale of General Health Questionnaire (GHQ-28) "somatic symptoms" and the scale of negative emotions $(\mathrm{r}=.585, p=.000)$, between the subscale of "anxiety/insomnia" and the scale of negative emotions $(\mathrm{r}=.310, p=.000)$ between the subscale of "social dysfunction" and the scale of negative emotions $(\mathrm{r}=.497, p$ $=.000$ ), as well between the subscale of "severe depression" and the scale of negative emotions $(\mathrm{r}=.604, p=.000)$. Also, it was observed a negative linear correlation between the subscale of General Health Questionnaire (GHQ-28) "somatic symptoms" and the scale of positive emotions $(\mathrm{r}=-.219, p=.000)$ and of medium power negative correlation between the subscale "anxiety/insomnia" and the scale of positive emotions $(\mathrm{r}=-.470, p=.000)$ as well between the subscale "social dysfunction" and the scale of positive emotions $(\mathrm{r}=-.244, p=.000)$. Finally, it was found of weak to medium power negative correlation between the subscale "severe depression" and the scale of positive emotions $(\mathrm{r}=-.391, p=.000)$.

The above results show that resilience and positive emotions are associated with better psychosomatic health both in total scale, as well in the respective subscales of the General Health Questionnaire (GHQ-28). It was also found that negative emotions are associated with worse psychosomatic health, both in total scale, as well in the respective subscales of the General Health Questionnaire (GHQ-28).

Regarding gender differences, it was observed statistically significant gender mean differences on the psychosomatic health (Table 3), with females to show higher mean value in GHQ-28 than male cadets $(\mathrm{t}=-4.599, p=.016)$, which means that males present statistically significant better psychosomatic health than female cadets.

Also about the subscales of the General Health Questionnaire (GHQ-28), the gender appears to be a factor that is correlated statistically significant with the subscales "somatic symptoms" and "anxiety/insomnia" (Table 3). Specifically, females present a higher mean value in the subscale of "somatic symptoms" in relation to males ( $\mathrm{t}=$ -4.499, $p=.016$ ), as well, females present higher mean value in the subscale "anxiety/ insomnia", in relation to males $(\mathrm{t}=-5.956, p=.000)$.

Regarding academic year differences, it was found statistically significant mean differences on General Health (GHQ-28) (Table 4), with the $1^{\text {st }}$ year cadets to present higher mean value on the General Health Questionnaire (GHQ-28) in relation to $2^{\text {nd }}$ year cadets $(\mathrm{t}=1.029, p=.034)$, which means that $2^{\text {nd }}$ year cadets have statistically significant better psychosomatic health than freshmen. 
Table 3. Comparison of mean values (M) and standard deviations (SD) between the general health and its subscales with gender.

\begin{tabular}{|c|c|c|c|c|c|}
\hline & \multicolumn{2}{|c|}{$\begin{array}{l}\text { Females } \\
\mathrm{N}=123 \\
\mathrm{M}(\mathrm{SD})\end{array}$} & \multicolumn{2}{|c|}{$\begin{array}{c}\text { Males } \\
\mathrm{N}=272 \\
\mathrm{M}(\mathrm{SD})\end{array}$} & \multirow[t]{2}{*}{$t^{1}$} \\
\hline & M & SD & M & $\mathrm{SD}$ & \\
\hline General Health & 25.89 & 12.436 & 20.30 & 10.560 & $-4.599^{*}$ \\
\hline Somatic Symptoms & 7.87 & 4.299 & 5.97 & 3.697 & $-4.499^{*}$ \\
\hline Anxiety/Insomnia & 8.69 & 4.927 & 5.98 & 3.797 & $-5.956^{\star *}$ \\
\hline Social Dysfunction & 6.47 & 3.017 & 6.07 & 3.081 & -1.221 \\
\hline Severe Depression & 2.84 & 3.973 & 2.27 & 3.343 & -1.477 \\
\hline
\end{tabular}

${ }^{*} p<.05 .{ }^{* *} p<.01 .{ }^{1}$ t-test for independent samples.

Table 4. Mean Comparisons (M) and Standard Deviations (SD) between general health and its subscales with academic year.

\begin{tabular}{|c|c|c|c|c|c|}
\hline & \multicolumn{2}{|c|}{$\begin{array}{l}1^{\text {st }} \text { year } \\
\mathrm{N}=214 \\
\mathrm{M}(\mathrm{SD})\end{array}$} & \multicolumn{2}{|c|}{$\begin{array}{l}2^{\text {nd }} \text { year } \\
\mathrm{N}=181 \\
\mathrm{M}(\mathrm{SD})\end{array}$} & \multirow[t]{2}{*}{$t^{1}$} \\
\hline & M & $\mathrm{SD}$ & M & SD & \\
\hline General Health & 22.59 & 12.280 & 21.40 & 10.401 & $1.029^{\star}$ \\
\hline Somatic Symptoms & 6.75 & 4.078 & 6.34 & 3.877 & 1.029 \\
\hline Anxiety/Insomnia & 7.16 & 4.632 & 6.42 & 3.989 & 1.691 \\
\hline Social Dysfunction & 5.91 & 3.142 & 6.54 & 2.939 & -2.046 \\
\hline Severe Depression & 2.75 & 3.774 & 2.09 & 3.253 & 1.852 \\
\hline
\end{tabular}

${ }^{*} p<.05 .{ }^{* *} p<.01 .{ }^{1}$ t-test for independent samples.

\section{Prediction of Psychosomatic Health and Resilience}

In order to test if the independent variables of 1) positive emotions, 2) negative emotions and 3) resilience can predict psychosomatic health, the stepwise multiple regression was applied.

In stepwise multiple regression, negative emotions were entered as first independent variable which was found to be responsible for $36.4 \%$ of the variance of psychosomatic health $\left(\mathrm{F}_{1,393}=225.30, p=.000\right)$. Resilience was entered in the next step and it was responsible for an additional $12 \%\left(\mathrm{~F}_{1,392}=91.22, p=.000\right)$. Finally, positive emotions were added which were responsible for an additional $2.9 \%\left(\mathrm{~F}_{1,391}=23.13, p=.000\right)$. Therefore, $51.3 \%$ of the variance of psychosomatic health can be interpreted by these three (3) independent variables. By inspecting B-values, we can see that the above independent variables contribute significantly to the prediction of the psychosomatic health and more specifically, negative emotions by $\mathrm{B}=.51, \mathrm{t}=14.21, p=.000$, resilience by $\mathrm{B}=-.24, \mathrm{t}=-5.74, p=.000$ and positive emotions by $\mathrm{B}=-.20, \mathrm{t}=-4.81, p=.000$. Therefore, it can be seen that the independent variable of negative emotions has a positive association with psychosomatic health (GHQ-28) and for that reason, increased 
levels of negative emotions has as a result increased problems in psychosomatic health. Regarding the independent variable of resilience and that of positive emotions, it was found that they were associated negatively with psychosomatic health (GHQ-28) and therefore, increased levels of resilience and positive emotions have as a result, lower number of problems in psychosomatic health (Table 5).

The stepwise multiple regression was also used in order to predict Resilience. As independent variables were used: 1) psychosomatic health, 2) positive emotions and 3) negative emotions. In stepwise multiple regression, positive emotions were entered first as independent variable, which has found to be responsible for $29.9 \%$ of variance of resilience $\left(\mathrm{F}_{1,393}=167.43, p=.000\right)$. Psychosomatic health was entered as $2^{\text {nd }}$, and it was found to be responsible for an additional $7.8 \%\left(\mathrm{~F}_{1,392}=48.83, p=.000\right)$, while the independent variable of negative emotions found not able to explain an additional part of variance of resilience. Therefore, $37.6 \%$ of variance of resilience can be interpreted from these two (2) independent variables. By inspecting the B-values, we can see that the above independent variables, contribute significantly to the prediction of resilience and specifically, positive emotions by $\mathrm{B}=.42, \mathrm{t}=9.61, p=.000$, and psychosomatic health by $\mathrm{B}=-.31, \mathrm{t}=-6.98, p=.000$. Therefore, it appears that the independent variable of positive emotions has positive correlation with resilience and, for that reason, increased positive emotions results in increased resilience. Regarding the independent variable of psychosomatic health, it was found that it is correlated negatively with resilience and therefore, higher number of psychosomatic health problems are related to decreased level of resilience, while, on the contrary, low number of psychosomatic health problems are related with increased level of resilience (Table 6).

\section{General Discussion}

This study confirms the value of positive emotions which, unlike negative emotions, contribute substantially to the building and enhancement of resilience, which is a challenge particularly for Military Academies. In particular, the focus of the Military Academies in the cultivation of positive emotions, instead of eliminating negative emotions, can contribute greatly to enhance the resilience of cadets. Even more, the recognition

Table 5. Stepwise multiple regression of predictor variables for psychosomatic health.

\begin{tabular}{ccccccc}
\hline Variable & $\mathrm{R}$ & $\mathrm{B}$ & $\mathrm{SE} . \mathrm{b}$ & Beta & $\mathrm{t}$ & Significance of t \\
\hline Negative emotions & .60 & .90 & .06 & .51 & 14.21 & .000 \\
Resilience & .69 & -.24 & .04 & -.24 & -5.74 & .000 \\
Positive emotions & .71 & -.35 & .07 & -.20 & -4.80 & .000 \\
\hline
\end{tabular}

Table 6. Stepwise multiple regression of predictor variables for resilience.

\begin{tabular}{ccccccc}
\hline Variable & $\mathrm{R}$ & $\mathrm{B}$ & SE. b & Beta & $\mathrm{t}$ & Significance of t \\
\hline Positive emotions & .55 & .74 & .08 & .42 & 9.61 & .000 \\
psychosomatic health & .61 & -.31 & .04 & -.31 & -6.98 & .000 \\
\hline
\end{tabular}


of the adaptive value of positive emotions can contribute essentially to the unfolding of better physical and mental performance of cadets, as well to the reduction of maladjusted reactions.

In addition, the results confirm the effectiveness of positive emotions and resilience to the development and maintenance of good psychosomatic health for the cadets of the NCO Military Academy. Those results also reinforce the argument that Military Academies can invest in the cultivation of positive emotions and enhance resilience in order to generate healthier, more efficient and more creative cadets as well to reduce the health care costs to treat disorders that are related to the absence of the previous concepts. In other words, by showing the effectiveness of positive emotions as well as their relation with resilience, can create those prerequisites for the development of programs in Military Academies, similar to the aforementioned CSF2 program, which will be able to take advantage of positive emotions towards enhancing resilience and strengthening psychosomatic health of their cadets.

Moreover, as it was shown that there are no differences on positive and negative emotions as well on resilience, according to gender and the academic year to the NCO Military Academy, however, it was observed that males as well $2^{\text {nd }}$ year cadets present statistically significant better psychosomatic health than females and $1^{\text {st }}$ year cadets, respectively. Particularly, with regard to female participants, it can be seen that they show statistically significant higher mean value on subscales of "somatic symptoms" and "anxiety/insomnia", in comparison with the male cadets. This find is in line with the study of Bartone \& Priest (2001) in US Military Academy at West Point. Also this find lead to the hypothesis that both female students and freshmen of the NCO Military Academy, are using positive emotions and develop resilience as an adaptation strategy and effective response to the high physical and mental requirements of the Military Academy. However, this hypothesis must be investigated in a longitudinal study that will examine the interaction of thestudied variables as well as other related factors.

Finally, statistical analysis revealed the toxic effect of negative emotions as they can predict strongly and significantly the bad psychosomatic health, while positive emotions can predict significantly the good psychosomatic health and increased resilience. Moreover, increased resilience appears to predict significantly the good psychosomatic health, and vice versa. Therefore, because within the Army context is in most cases impossible to eliminate the negative emotions due to the nature of the military lifestyle, it is considered essential to strengthen positive emotions and resilience of the cadets.

\section{Conclusion}

A limitation of this study is the fact that the results are based on correlational results and this does not allow to claim cause-effect model, about the relations of variables under study. This study is the first one of this type that was conducted in cadets in Greece, in order to give an emphasis on the fact that positive emotions and their close relation to the development of resilience, psychosomatic health and psychological well-being, can lead to multiple benefits to organizations like Army, firstly by creating measurable 
more efficient and creative soldiers and also by reducing health care costs arising from the treatment of staff, due to the absence of these crucial benefits.

\section{References}

Affleck, G., \& Tennen, H. (1996). Construing Benefits from Adversity: Adaptational Significance and Dispositional Underpinnings. Journal of Personality, 64, 899-922. http://dx.doi.org/10.1111/j.1467-6494.1996.tb00948.x

Bartone, P. T., \& Priest, R. F. (2001). Sex Differences in Hardiness and Health among West Point Cadets. Presented at the 13th Annual Convention of the American Psychological Society, Toronto.

Block, J., \& Kremen, A. M. (1996). IQ and Ego-Resiliency: Conceptual and Empirical Connections and Separateness. Journal of Personality and Social Psychology, 70, 349-361.

http://dx.doi.org/10.1037/0022-3514.70.2.349

Block, J. H., \& Block, J. (1980). The Role of Ego-Control and Ego-Resiliency in the Origination of Behavior. In W. A. Collings (Ed.), The Minnesota Symposia on Child Psychology (Vol. 13, pp. 39-101). Hillsdale, NJ: Erlbaum.

Bonanno, G. A., Galea, S., Bucciarelli, A., \& Vlahov, D. (2007). What Predicts Psychological Resilience after Disaster. The Role of Demographics, Resources, and Life Stress. Journal of Consulting and Clinical Psychology, 75, 671-682. http://dx.doi.org/10.1037/0022-006X.75.5.671

Casey, G. W. (2011). Comprehensive Soldier Fitness. A Vision for Psychological Resilience in the U.S. Army. American Psychologist, 66, 1-3. http://dx.doi.org/10.1037/a0021930

Connor, K. M., \& Davidson, J. R. T. (2003). Development of a New Resilience Scale: The ConnorDavidson Resilience Scale (CD-RISC). Depression and Anxiety, 18, 76-82.

http://dx.doi.org/10.1002/da.10113

Cornum, R., Matthews, M. D., \& Seligman, M. (2011). Comprehensive Soldier Fitness: Building Resilience in a Challenging Institutional Context. American Psychologist, 66, 4-9. http://dx.doi.org/10.1037/a0021420

Dascalou, B., \& Sigkollitou, E. (2011). Positive and Negative Affectivity Schedule (PANAS). In A. Stalikas, S. Triliva, \& P. Roussi (Eds.), The Psychometric Tools in Greece. Athens: Greek Letters.

Davis, C. G., Nolen-Hoeksema, S., \& Larson, J. (1998). Making Sense of Loss and Benefiting from the Experience: Two Construals of Meaning. Journal of Personality and Social Psychology, 75, 561-574. http://dx.doi.org/10.1037/0022-3514.75.2.561

Dimitriadou, E., \& Stalikas, A. (2011). The Connor-Davidson Resilience Scale (CD-RISC). In A. Stalikas, S. Triliva, \& P. Roussi (Eds.), The Psychometric Tools in

Folkman, S., \& Moskowitz, J. T. (2000). Positive Affect and the Other Side of Coping. American Psychologist, 55, 647-654. http://dx.doi.org/10.1037/0003-066X.55.6.647

Fredrickson, B. L. (1998). What Good Are Positive Emotions. Review of General Psychology: Special Issue: New Directions in Research on Emotion, 2, 300-319. http://dx.doi.org/10.1037/1089-2680.2.3.300

Fredrickson, B. L. (2001). The Role of Positive Emotions in Positive Psychology: The Broadenand-Build Theory of Positive Emotions. American Psychologist: Special Issue, 56, 218-226. http://dx.doi.org/10.1037/0003-066X.56.3.218

Fredrickson, B. L., \& Joiner, T. (2002). Positive Emotions Trigger Upward Spirals toward Emotional Well-Being. Psychological Science, 13, 172-175.

http://dx.doi.org/10.1111/1467-9280.00431 
Fredrickson, B. L., \& Levenson, R. W. (1998). Positive Emotions Speed Recovery from the Cardiovascular Sequelae of Negative Emotions. Cognition and Emotion, 12, 191-220. http://dx.doi.org/10.1080/026999398379718

Fredrickson, B. L., \& Losada, M. F. (2005). Positive Affect and the Complex Dynamics of Human Flourishing. American Psychologist, 60, 678-686. http://dx.doi.org/10.1037/0003-066X.60.7.678

Fredrickson, B. L., Mancuso, R. A., Branigan, C., \& Tugade, M. M. (2000). The Undoing Effect of Positive Emotions. Motivation and Emotion, 24, 237-258. http://dx.doi.org/10.1023/A:1010796329158

Fredrickson, B. L., Tugade, M. M., Waugh, C. E., \& Larkin, G. R. (2003). What Good Are Positive Emotions in Crisis. A Prospective Study of Resilience and Emotions Following the Terrorist attacks on the United States on September 11th, 2001. Journal of Personality \& Social Psychology, 84, 365-376. http://dx.doi.org/10.1037/0022-3514.84.2.365

Garyfallos, G., Karastergiou, A., Adamopoulou, A., Moutzoukis, C., Alagiozidoy, E., Mala, O. (1991). Greek Version of the General Health Questionnaire: Accuracy of Translation and Validity. Acta Psychiatrica Scandinavica, 84, 371-378. http://dx.doi.org/10.1111/j.1600-0447.1991.tb03162.x

Gold, M. A., \& Friedman, S. B. (2000). Cadet Basic Training: An Ethnographic Study of Stress and Coping. Military Medicine, 165, 147-152.

Goldberg, D. P., \& Hillier, V. F. (1979). A Scaled Version of the General Health Questionnaire. Psychological Medicine, 9, 139-145. http://dx.doi.org/10.1017/S0033291700021644

Hobson, C. J., Kamen, J., Szostek, J., Nethercut, C. M., Tiedmann, J. W., \& Wojnarowicz, S. (1998). Stressful Life Events: A Revision and Update of the Social Readjustment Rating Scale. International Journal of Stress Management, 5, 1-23. http://dx.doi.org/10.1023/A:1022978019315

Klohnen, E.C. (1996). Conceptual Analysis and Measurement of the Construct of Ego Resiliency. Journal of Personality and Social Psychology, 70, 1067-1079. http://dx.doi.org/10.1037/0022-3514.70.5.1067

Kobasa, S. C. (1979). Stressful Life Events, Personality, and Health-Inquiry into Hardiness. Journal of Personality and Social Psychology, 37, 1-11. http://dx.doi.org/10.1037/0022-3514.37.1.1

Lazarus, R. S. (1993). From Psychological Stress to the Emotions: A History of Changing Outlooks. Annual Review of Psychology, 44, 1-21. http://dx.doi.org/10.1146/annurev.ps.44.020193.000245

Luthar, S. S., Cicchetti, D., \& Becker, B. (2000). The Construct of Resilience: A Critical Evaluation and Guidelines for Future Work. Child Development, 71, 543-562. http://dx.doi.org/10.1111/1467-8624.00164

Lyubomirsky, S., Tkach, C., \& DiMatteo, M. R. (2006). What Are the Differences between Happiness and Self-Esteem. Social Indicators Research, 78, 363-404. http://dx.doi.org/10.1007/s11205-005-0213-y

Maddi, S. R., \& Khoshaba, D. M. (2005). Resilience at Work: How to Succeed No Matter What Life Throws at You. New York: AMACOM.

Masten, A. S., \& Reed, M. J. (2002). Resilience in Development. In C. R. Snyder, \& S. J. Lopez (Eds.), Handbook of Positive Psychology (pp. 117-131). New York: Oxford University Press.

Masten, A. S., \& Wright, M. O. (2010). Resilience over the Lifespan: Developmental Perspectives on Resistance, Recovery, and Transformation. In J. W. Reich, A. J. Zautra, \& J. S. Hall (Eds.), Handbook of Adult Resilience (pp. 213-237). New York: The Guilford Press.

Matthews, M. (2008). Toward a Positive Military Psychology. Military Psychology, 20, 289-298. 
http://dx.doi.org/10.1080/08995600802345246

Mroczek, D. K., \& Spiro, A. (2005). Change in Life Satisfaction during Adulthood: Findings from The Veterans Affairs Normative Aging Study. Journal of Personality and Social Psychology, 88, 189-202. http://dx.doi.org/10.1037/0022-3514.88.1.189

Myers, J. E., \& Bechtel, A. (2004). Stress, Wellness, and Mattering among Cadets at West Point: Factors Affecting a Fit and Healthy Force. Military Medicine, 169, 475-482. http://dx.doi.org/10.7205/MILMED.169.6.475

Pietrzak, R. H., Johnson, D. C., Goldstein, M. B., Malley, J. C., Rivers, A. J., Morgan, C. A., \& Southwick, S. M. (2010). Psychosocial Buffers of Traumatic Stress, Depressive Symptoms, and Psychosocial Difficulties in Veterans of Operations Enduring Freedom and Iraqi Freedom: The Role of Resilience, Unit Support, and Postdeployment Social Support. Journal of Affective Disorders, 120, 188-192. http://dx.doi.org/10.1016/j.jad.2009.04.015

Riolli, L., Savicki, V., \& Spain, E. (2010). Positive Emotions in Traumatic Conditions: Mediation of Appraisal and Mood for Military Personnel. Military Psychology, 22, 207-223. http://dx.doi.org/10.1080/08995601003638975

Seligman, M. E. P., \& Csikszentmihalyi, M. (Eds.) (2000). Positive Psychology-An Introduction. American Psychologist, 55, 5-14. http://dx.doi.org/10.1037/0003-066X.55.1.5

Tugade, M., \& Fredrickson, B. (2004). Psychological Resilience and Positive Emotional Granularity: Examining the Benefits of Positive Emotions on Coping and Health. Journal of Personality, 72, 1161-1190. http://dx.doi.org/10.1111/j.1467-6494.2004.00294.x

Tugade, M., \& Fredrickson, B. (2004). Resilient Individuals Use Positive Emotions to Bounce Back from Negative Emotional Experiences. Journal of Personality and Social Psychology, 86, 320-333.

Tugade, M. M., \& Fredrickson, B. L. (2002). Positive Emotions and Emotional Intelligence. In L. F. Barrett, \& P. Salovey (Eds.), The Wisdom of Feelings (pp. 319-340). New York: Guilford.

Watson, D., Clark, L. A., \& Tellegen, A. (1988). Development and Validation of Brief Measures of Positive and Negative Affect: The PANAS Scales. Journal of Personality and Social Psychology, 54, 1063-1070. http://dx.doi.org/10.1037/0022-3514.54.6.1063

Williams, D. (1999). Life Events and Career Change: Transition Psychology in Practice. British Psychological Society Occupational Psychology Conference. Leicester: British Psychological Society.

\section{Submit or recommend next manuscript to SCIRP and we will provide best service for you:}

Accepting pre-submission inquiries through Email, Facebook, LinkedIn, Twitter, etc. A wide selection of journals (inclusive of 9 subjects, more than 200 journals)

Providing 24-hour high-quality service

User-friendly online submission system

Fair and swift peer-review system

Efficient typesetting and proofreading procedure

Display of the result of downloads and visits, as well as the number of cited articles

Maximum dissemination of your research work

Submit your manuscript at: http://papersubmission.scirp.org/

Or contact psych@scirp.org 